\title{
Towards Preserving Transylvanian Fortified Churches in Virtual Reality
}

\author{
Mihai Duguleana ${ }^{(\bowtie)}$ and Cristian Cezar Postelnicu \\ Transylvania University of Brasov, Brasov, Romania \\ mihai.duguleana@unitbv.ro
}

\begin{abstract}
A fortified church is a building which has a religious meaning, but also played a defensive role in times of war. Many fortified churches from countries such as Romania, Slovenia, Switzerland, Poland, France, Denmark, Portugal, Germany or Belarus featured thick walls and high battlements and embrasures. However, Middle Age fortified churches are different from castles and fortresses because they were designed to protect small communities. Transylvania hosts the highest number of fortified churches from Europe. In the medieval ages, more than 300 churches were built by the inhabitants of this area. This was the direct result of the constant invasions from the Ottomans and other nomad populations such as Tatars. Many of these edifices date since the $13^{\text {th }}$ century, but some are in an advanced state of degradation, caused mainly by poor preservation measures and lack of interest from the local authorities.

This paper introduces a system which aims to increase the awareness about the fortified churches from a small area of Transylvania called "Țara Bârsei". Our focus is on the visual preservation of several of these monuments through the technique of photogrammetry, as well as the implementation of a stand which would attract the potential tourists. The key idea of our study is to influence them to visit several churches by placing next to each other in Virtual Reality both mainstream and low-profile objectives. We assess users' opinion about a holographic stand commanded by a mobile application which includes the $3 \mathrm{D}$ models, pictures and a short description of the fortified churches based on a modified HARUS questionnaire. Results show increased interest, directly resulted from the visualization technology.
\end{abstract}

Keywords: Transylvanian fortified churches $\cdot$ Cultural heritage Preservation

\section{Introduction}

A high concentration of fortified churches can be seen in places where there was a lot of hand-to-hand warfare, such as the Dordogne region of France, which was fought over by France and England in medieval times, and in Transylvania, which was the scene of Ottoman invasions. Some other places in Europe with fortified churches can be seen in Fig. 1.

Transylvania was called "the gate of Europe". This Romanian territory has the highest number of Saxon villages from Europe. These formed starting with the $12^{\text {th }}$ century, after the Hungarians began to infuse the local population with German 


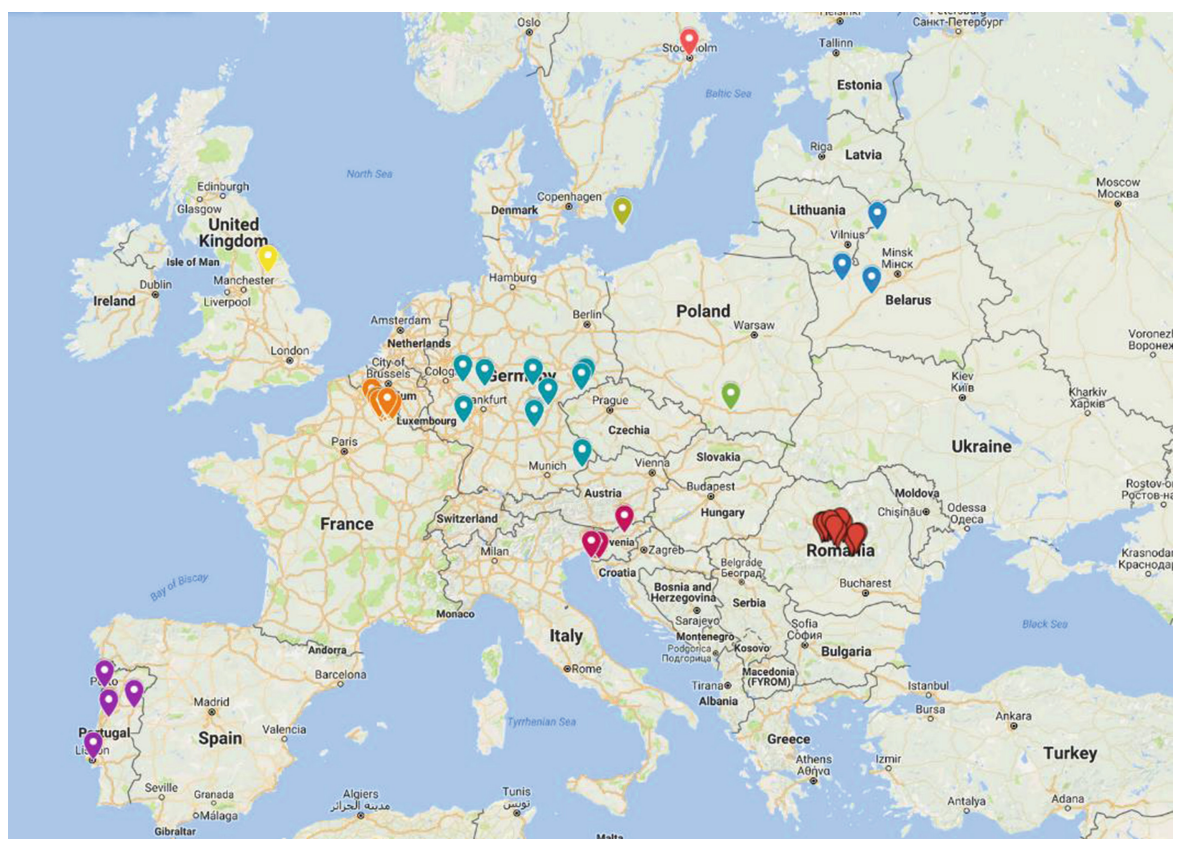

Fig. 1. Europe's most prominent fortified churches.

colonists, in an effort to annex the territory. However, the Saxons blended well with the natives and some of the elements of their civilization managed impose over the older practices. One of these is their architecture. As the area was constantly under threat from Ottomans and Tatars, one of the most adopted elements is the fortification style. The common approach against invaders was the "high price for a small benefit" strategy. In most of the cases, raiding the churches was too hard to be worth the trouble. In fact some of the churches were never conquered. Such is the case of Prejmer Fortified Church, which featured thick walls and unique defensive systems such as the "Organ of death" (see Fig. 2).

A context information which is worth mentioning is the advanced degradation state of some of these fortified churches. The 7 Transylvanian villages with fortified churches which are listed in the UNESCO World Heritage index (Biertan, Câlnic, Dârjiu, Prejmer, Saschiz, Valea Viilor and Viscri) are at the moment well preserved and constantly taken care of. However, many others are on the verge of collapsing. If this happens, the consequences are so severe, the monument is probably lost forever (see the case of the Rotbav fortified church in Fig. 3).

A study from 2011 shows that although some of the UNESCO churches listed above are well-known, there are others which are also popular among the local population. These are Cisnădie, Cisnădioara, Agnita and Slimnic. However, not being listed in UNESCO index makes them virtually invisible to the foreign tourists, according to [2]. 


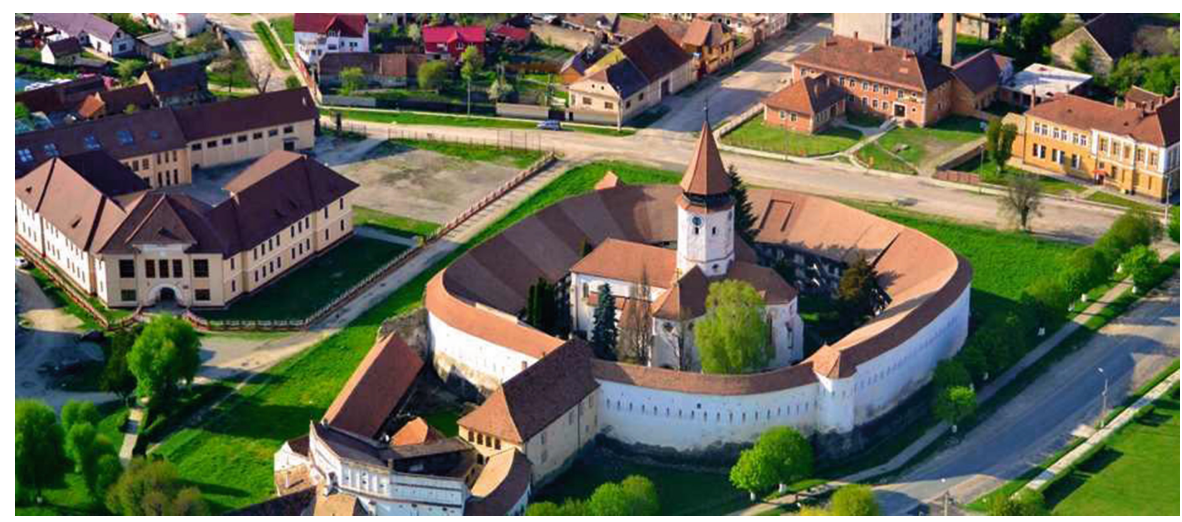

Fig. 2. Prejmer Fortified Church.

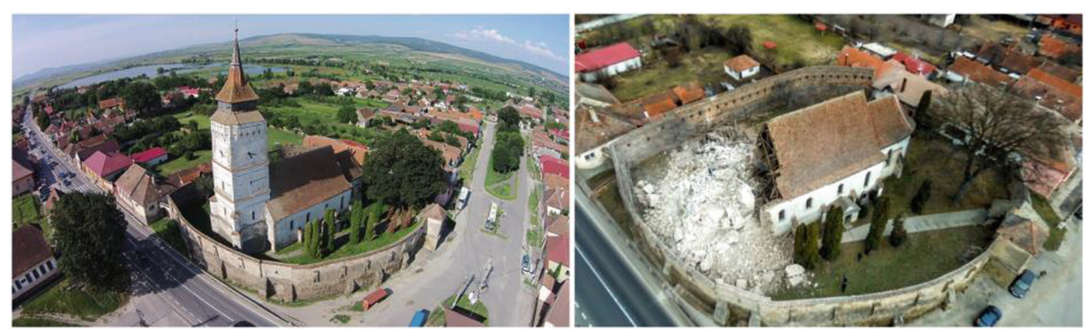

Fig. 3. Rotbav Fortified Church before and after collapsing in 2016.

Several researchers tried to find the possibilities of development of these areas, considering their rich cultural heritage. E.g. in [3], authors propose a set of long-term actions which they think it will act towards the preservation and the development of these settlements. However, some of these activities have been undergone in the past by local authorities and decisional factors, with little or no success. It is showed in [4] that the problems are more severe than what authorities initially thought. The Saxons, the population which maintained the fortified churches and the old village centers, have left Romania in the exodus which occurred right after the revolution from 1989. Many of the buildings are either uninhabited or were bought by new owners, which modernized them without considering the idea of preserving the past looks (materials, shapes and colors). Although this region is important on multiple levels (i.e. it hosts a unique habit [5]), the poor road infrastructure and the nonexistent regional strategy for tourism have contributed to the decay.

One idea which seem to catch was ecotourism [6]. However, ecotourism needs to be naturally sustained by an organic growth of visitors, resulted directly from a constant activity and a reasonable long-term preservation strategy, engaging enough to catch the interest of the newer generations of tourists, travelers and other stakeholders. Another idea which seemed to multiply the awareness effects was to ease the return of the Saxons, which are occasionally traveling to Romania to visit their homeland [7]. 
However, the amplitude of this phenomena is low, compared to the average numbers of tourists from the region. Even the most well-known fortified church from Transylvania, Viscri, is still struggling to implement a Western model of heritage management which will eventually allow better engagement with visitors, higher touristic rating and in the end, larger audience [8].

\subsection{Types of Fortified Churches}

According to [1] there are 3 types of fortified churches in Transylvania:

- Churches with fortified walls - the church itself is not a defensive structure, but it is surrounded by walls which fulfill this function. One good example is Prejmer Fortified Church (see Fig. 2).

- Fortified churches - the church's body is a defensive construction, and the outside fortifications are not present or if they are, they are not actually playing a defensive role. Large churches with thick walls such as Feldioara can be included here.

- Fortress churches - the fortified walls are provided with fortified storerooms for supplies and fortified with towers, bastions and warehouses, often being surrounded by a water channel. Fortress churches are related to notion of "citadel", but they differ because they were not permanently inhabited, but only in case of war and siege (see Fig. 4).

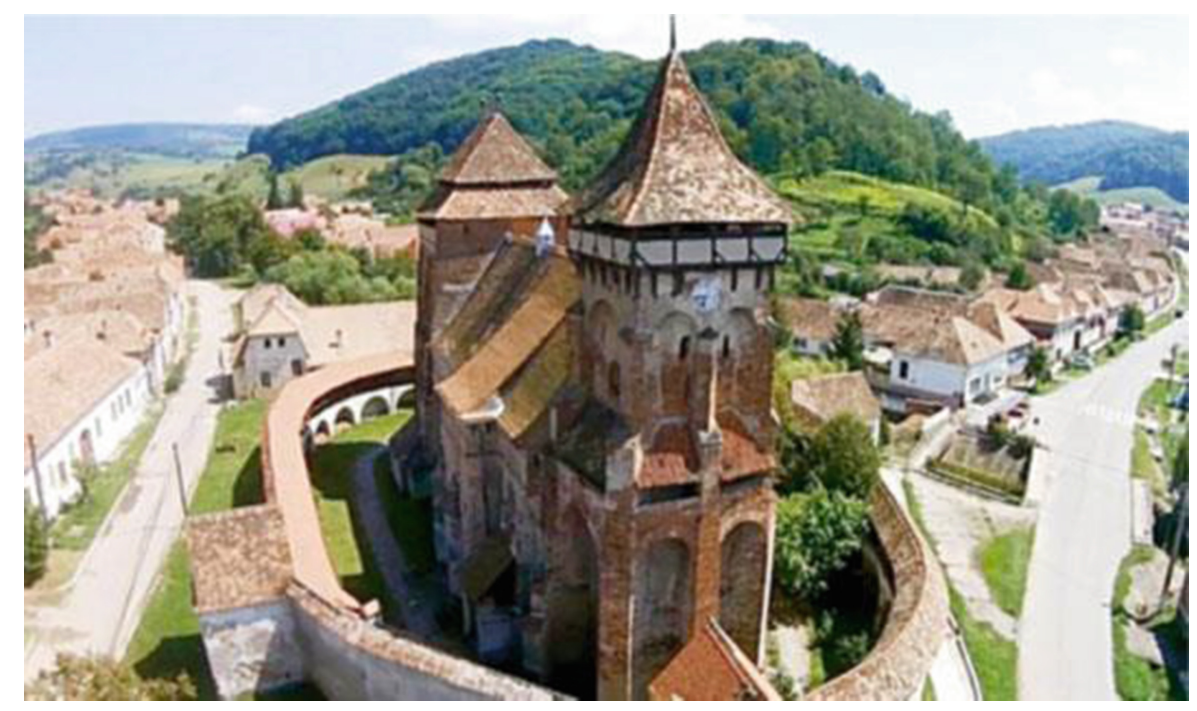

Fig. 4. Valea Viilor fortress church

Transylvanian fortified churches are fairly different from the ones built in the Western Europe, as their purpose was different. While Western Europe fortified churches belong to religious cults such as the Templars, or to the Catholic Church, and hosted only sacred relics and books, the Transylvanian fortified churches were 
supposed to offer protection against invaders for the tens of families for each of the villages which had them. Very often, each family had their own cellar in which they could store separately their belongings.

\subsection{Study Objectives}

This paper presents the main opportunities, limitations and challenges posed by applying the process of photogrammetry to some of the fortified churches from a small area of Transylvania called "Țara Bârsei” from several points of view: technical, social and financial. Our study also proposes the development of a multi-language holographic stand which is able to output information about the fortified churches to visitors of a museum, gallery or any other kind of cultural heritage related exhibition. Making use of the holographic effect obtained from the reflection of the image outputted by flat monitor into a glass pyramid, the holographic stand can display various 3D models, animations and other types of visual effects. Thus, it is perfect to showcase the small yet very detailed 3D models of the churches from Tara Bârsei. In order to make to system more interactive, the physical device was coupled with a smartphone application which allows users to select their desired monument from a stylized historic map of the area (see Fig. 5). The application contains information on the most important fortified churches from Transylvania, which are both interesting touristic sites as well low marketed destinations.
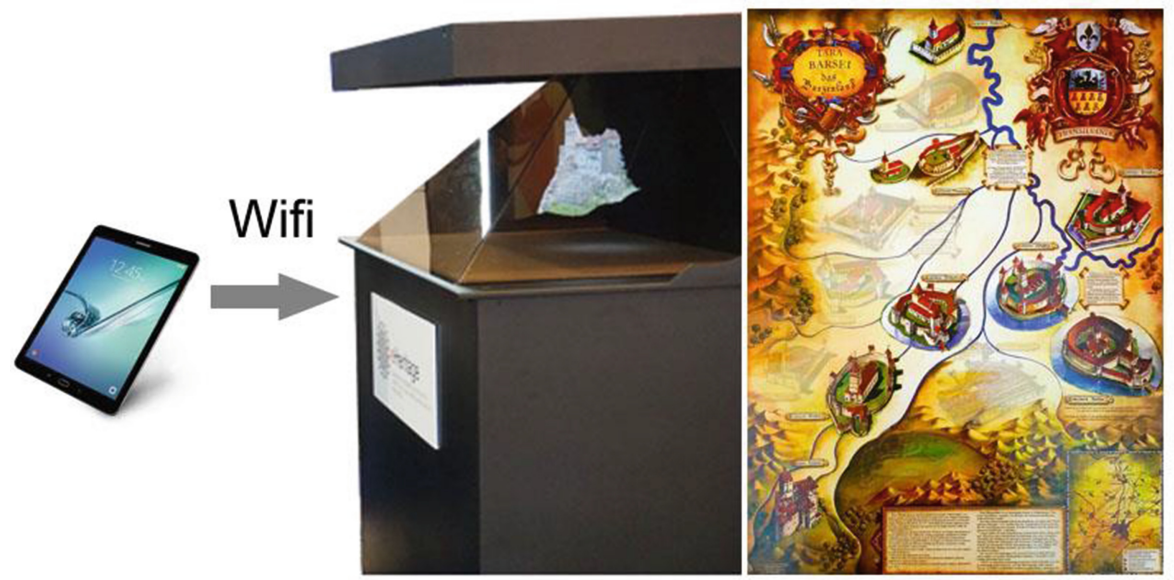

Fig. 5. The holographic stand, the tablet and the main page of the application

Our final aims are to discover which the best means of digitally conserving these monuments, to implement a system which will enhance the visibility of less-known fortified churches from Transylvania and to assess the perception of the proposed implementation by the general public and by experts in the field of cultural heritage. On a side note, we wanted to build accurate 3D models for all the fortified churches from this region and to offer these for free to the cultural heritage enthusiasts, within an 
online repository. In order to accomplish these goals, we needed to interact with the representatives of the fortified churches, to ask permission to photograph and inspect the landmarks. Deriving from discussions with the curators, one idea which we hope to put in practice is to offer the developed system, the holostand presented in Fig. 5, to be displayed in the most visited churches from the regions, Prejmer and Harman, and perhaps, in the Bran castle. The purpose of this endeavor would be that tourists which are passing by would learn about the other churches and would want to also visit these, since all are very close one to the other. Although our study doesn't address the idea of a tour creation, the system proposed in this paper leaves tourists aware of the close proximity of similar landmarks, a piece of information which will help them decide on their next objective.

\section{Methods and Materials}

\subsection{Photogrammetry}

Photogrammetry is a technique which allows users to create 3D models from photos. We have used photogrammetry to build the 3D models presented in the holographic stand. The photogrammetry software used in most of the cases was Agisoft PhotoScan and Reality Capture. These programs allow users to import any kind of photo for the reconstruction phase. Thus, we have used several cameras, among which we can list Canon EOS 1300, Nikon D5300 and Samsung S8. In full compliance with this technique we notice that the higher resolution was used, the better were the results. Besides the photos taken from the surface level, use have used a drone (DJI Phantom 4 Pro) with $4 \mathrm{~K}$ lenses to catch the looks of the roofs and of the crannies and nooks of the architectural elements from upper body of the monuments. Agisoft produces weaker results in terms of resemblance, but can accept a higher number of images, whereas Reality Capture is limited to 2500 (for a standard license).

Other software used in our study was Blender and Meshlab (for trimming the models to an acceptable number of polygons) and Unity (for constructing the 3D slowrevolving setup for the glass pyramid).

Doing the field work, we've discovered that a typical church needs at least 20003000 photos in order to get a good 3D model. There are cases where, because of the large dimensions of the monument, we've used approximately 10000 photos to build the 3D model.

The process of taking photos for photogrammetry is not trivial. The photos need to be focused well. Any defocused/blurry image can ruin the model. Cameras were adjusted to get the best exposure (the best ratio between ISO, aperture, shutter speed and zoom). After the photo shooting sessions, the pictures need to be sorted for eliminating all the ill-focused ones. Finally, using the .raw format may require more space, but also proves to be the best choice, especially in the preprocessing phase.

On a side note, the best time to take the pictures is when it is cloudy, because the sun light influences the resulted textures. Thus, posing a wall directly illuminated by the sun light outputs overexposed colors and diminishes the details of the surface. 
Finally, computing the 3D model for medium quality may take even a week of continuous processing, using several connected servers.

In the post-processing phase, the surroundings which are not connected to the fortified church were cropped and the models were optimized to a smaller amount of polygons, in order to be ready for import in Unity.

\subsection{D Models}

Our team computed 3D models for the following fortified churches: Prejmer, Harman, Vulcan, Sanpetru, Maierus and Feldioara. Additionally, Rotbav, the church which collapsed in 2016, was modelled in CAD and showcased on the stand. There are several other fortified churches for which we are in the process of obtaining the authorizations to photograph them. Our final aim is to offer these models for free on the portal of the eHeritage Project, in the repository section [9].

\subsection{Holographic Stand}

The holographic stand uses the classic principle of holography: the image emitted from a highly luminous $4 \mathrm{~K}$ TV screen is reflected by a single-side reflexive glass mounted at an angle of $45^{\circ}$. Inside the glass construction, a white base lighten by a weak light source breaks the reflection sensation and creates the feeling of having the image reflected being inside the pyramid, instead of being on the surface of the glass. Thanks to the 3 reflections offered by the 3 sides of the pyramid, users can experience a greater sense of immersion.

The holographic stand undergone several changes since its initial concept presented in Fig. 6. The main improvement related to the shape of the glass pyramid. In order to increase the size of the holograms, instead of using a 4-face pyramid trunk, we have opted for using half of it. This translated in twice the space for the sides of the glass pyramid and also for the TV screen (instead of rendering 4 images, we need to render only 3). Other significant improvements are the exclusion of the Leap Motion device (as users can interact with the stand directly from the application installed on an Android tablet), the use of better and lighter materials (the first version was made from wood, while the second version was made from aluminum case and metal sheets sprayed in electrostatic field) and the use of castor wheels on the base, in order to make it mobile and easy to move. All these improvements we carried out at the recommendation of several museum custodians and gallery curators which explained us in detail the features of a museum-ready stand.

The system (in various versions) was presented at various events such the EU Open Day 2018 from Brussels, Belgium, AFCO 2018 from Brasov, Romania, Researchers Night from Brasov, Romania, Internet Festival 2017 from Pisa, Italy and the Lubec 2017 from Lucca, Italy. 

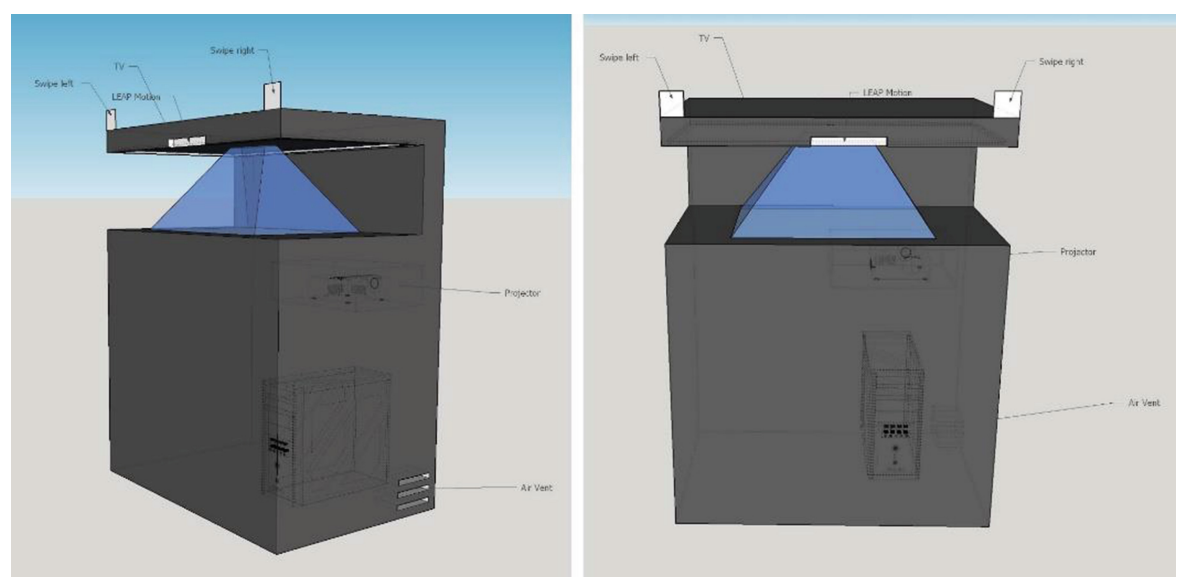

Fig. 6. The initial holographic stand prototype

\section{Evaluation}

14 people (11 males and 3 females) have taken the questionnaire presented in Table 1 during 2 separate events, AFCO 2018 and EU Open Day (although the stand was inspected by several hundreds, see Fig. 7). Most have never seen a holographic display and were thrilled about the experience. As it is the case with new technologies (e.g. the augmented reality (AR) applications for mobile phones [10]), people are attracted and excited partially due to the technology showcased and not necessarily because of the content. However, it was not the intention of this research to limit this phenomena - on the contrary, we wanted to capitalize the momentum offered by the holographic display which is something rarely seen by most people, and to build upon this in order to create some interest for the real objective of the study. As a results, many visitors from both events, even local people, became interested in visiting the fortified churches of Tara Barsei.

\subsection{Questionnaire}

Each participant was asked to fill in a modified version of the Handheld Augmented Reality Usability Scale questionnaire [11]. The HARUS questionnaire was developed to evaluate the comprehensibility and manipulability of AR applications for handheld devices. Since the system developed is not really an AR application, we have tweaked the questionnaire to cover the subject of our study, while preserving the statistical computation process behind it.

Thus, the first section, Personal Skills (Q1-Q3), was intended to create a baseline, derived from the degree of familiarity of the subjects with virtual reality and more particularly, with holography. The second section (Q4-Q11) aims to assess the usability of the holographic stand. Enjoyment (Q12-Q15) and Usefulness (Q16-Q19) derive directly from the HARUS design. Last but not least, the Empirical section tries to infer some common knowledge about the study itself, about the quality of the 3D 
Table 1. Evaluation questionnaire

\begin{tabular}{|c|c|}
\hline Personal skills & $\begin{array}{l}\text { Q1: Have you used VR technologies before? } \\
\text { Q2: Have you ever seen a hologram before? } \\
\text { Q3: Are you familiar with the principles of holography? }\end{array}$ \\
\hline Comprehensibility & $\begin{array}{l}\text { Q4: I thought that using the system requires a lot of mental effort } \\
\text { Q5: I thought the amount of information displayed on the screen of the } \\
\text { tablet was appropriate } \\
\text { Q6: I thought that the information displayed on screen of the tablet was } \\
\text { difficult to read } \\
\text { Q7: I felt that the system was responding fast enough } \\
\text { Q8: I thought that the information displayed on screen of the tablet was } \\
\text { confusing } \\
\text { Q9: I thought the words and symbols on screen of the tablet were easy to } \\
\text { read } \\
\text { Q10: I felt that the quality of the 3D models was good } \\
\text { Q11: I thought that the information displayed on screen was consistent }\end{array}$ \\
\hline Enjoyment & $\begin{array}{l}\text { Q12: I enjoyed using the system } \\
\text { Q13: I found the system unpleasant } \\
\text { Q14: I found the system exciting } \\
\text { Q15: I found the system boring }\end{array}$ \\
\hline Usefulness & $\begin{array}{l}\text { Q16: By using the holographic stand, I was able understand the location } \\
\text { of the fortified churches } \\
\text { Q17: By using the holographic stand, I was more interested in visiting } \\
\text { the fortified churches } \\
\text { Q18: By using the holographic stand, I was able understand more about } \\
\text { the history of "Tara Barsei" } \\
\text { Q19: By using the holographic stand, I am more likely to visit fortified } \\
\text { churches in the future }\end{array}$ \\
\hline Empirical & $\begin{array}{l}\text { Q20: Which 3D model was the most appealing? } \\
\text { Q21: Which 3D model was the most unpleasant? } \\
\text { Q22: Which fortified church would you be interesting in visiting the } \\
\text { most in the near future? }\end{array}$ \\
\hline
\end{tabular}

models presented to the public and about their intentions in the near future. All of the questions from sections Comprehensibility, Enjoyment and Usefulness use a 7-point Likert scale, ranging from 1 - "strongly disagree", to 7 - "strongly agree". As a side note, in some cases, the 22 questions were perceived as too many by some of the respondents.

\subsection{Results}

The empirical questions were used to tweak features such as the luminosity of the light source inside the pyramid, or the luminosity and the position of the light source inside the scenario built in Unity. The 3D models were calibrated to cover all the screen allowed by the dimensions of the glass. All the answers from sections 2, 3 and 4 were 


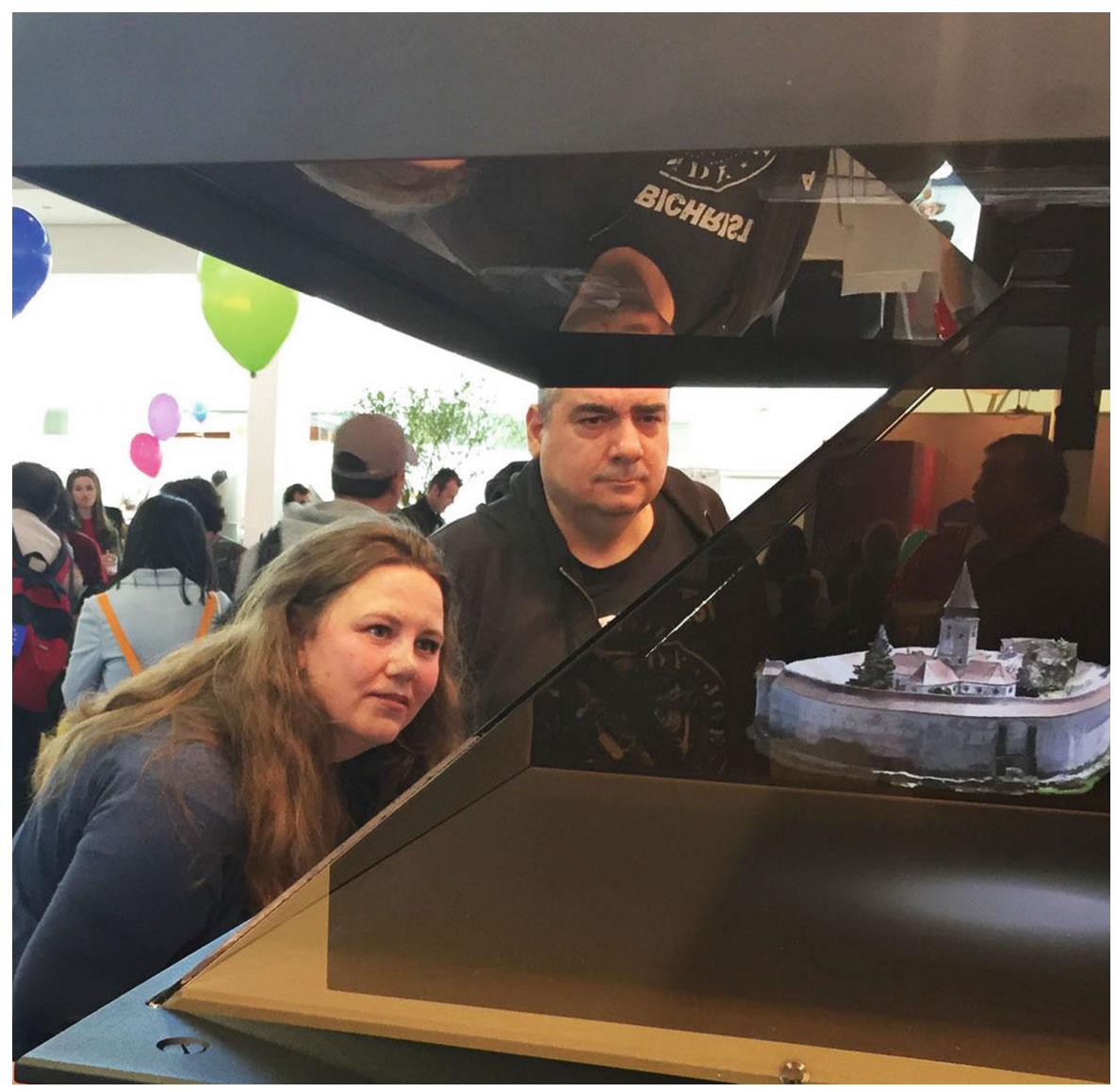

Fig. 7. The holographic stand at EU Open Day 2018, showcasing Prejmer fortified church

aggregated in order to obtain values for each of the 3 constructs: Comprehensibility, Enjoyment and Usefulness.

For each answer we inverted the results of the negatively stated items. After this action, we summed up all the values related to the specific construct and calculated the mean and the standard deviation. The obtained scores are mapped to a range of 0 to 100 , in order to see easier the percentiles. The results for each construct are the following: Comprehensibility $(\mathrm{M}=91.44 ; \quad \mathrm{SD}=2.12)$, Enjoyment $(\mathrm{M}=95.12$; $\mathrm{SD}=4.62)$ and Usefulness $(\mathrm{M}=89.27$; $\mathrm{SD}=4.82)$. We infer that the respondents easily understood the way to use the system, enjoyed the stand even more, and found the content delivered to be very useful (Fig. 8). 


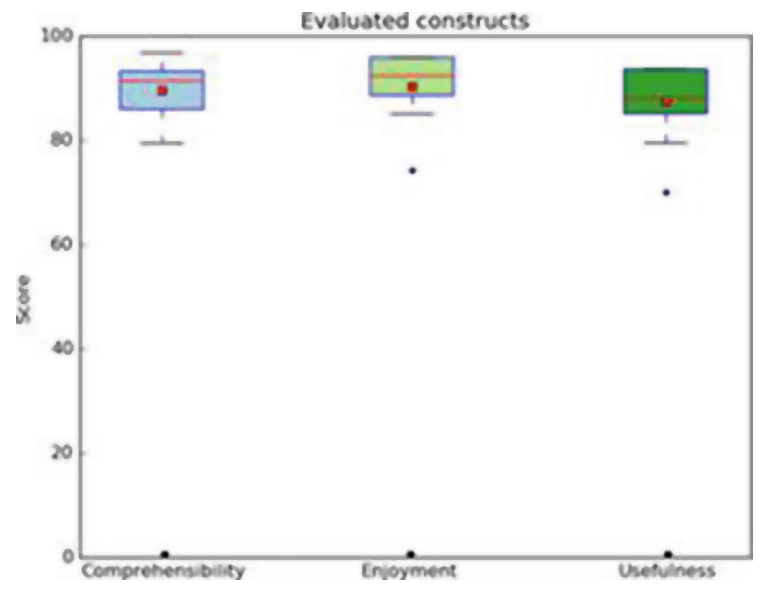

Fig. 8. Questionnaire results

\section{Conclusions and Future Developments}

As we initially thought, the system was very well received by all the participants of this study. Many praised the idea and the content, and even promised they will visit some of the fortified churches presented in the holographic stand, in the near future. However, there are still improvements to be made.

There are still 4 churches which need to be "photo-scanned" in order to obtain their 3D models and to put them in the application, not to mention the old city of Brasov, which we will most likely be represent by the fortress of Brasov. This means that additional 3D content needs to be developed.

Another way to develop the system is to add more interaction. Users like to interact with systems in a natural way. Using a mix between Leap Motion and the Andoird application installed on the tablet could prove worthy of investigating. Speaking of the application, one development which may have a greater impact would be to create an app which could be available to download for free on Google Play and IOS Marketplace, presenting the 3D models and historical facts about each of the monuments.

Other improvements related to the physical features of the holographic stand. We can improve the interior lighting of the glass pyramid, by investigating which light source is the best for holography (warm or cold) and which is the best light intensity. Last but not least, one of our future aims is to seal tight the stand and display it at several fortified churches from the area "Tara Barsei".

Acknowledgements. This paper is supported by European Union's Horizon 2020 research and innovation programme under grant agreement No 692103, project eHERITAGE (Expanding the Research and Innovation Capacity in Cultural Heritage Virtual Reality Applications). 


\section{References}

1. Valentina, S..S.: The Fortified Churches from Transylvania - How Well Are They Known By The Romanian Citizens? European Integration-New Challenges, 1948 (2011)

2. Muresan, A.: The fortified church of Biertan (Transylvania). In: Visitor Management, pp. 26-45 (2000)

3. Gabor, D.I., et al.: Possibilities for rural tourism development around fortified churches. Lucrări Științifice Manag. Agricol 15(4), 259 (2013)

4. Szaktilla, S.: The spirit of the Transylvanian fortified churches... The people have left, their buildings remain, pp. 1-10 (2008)

5. Akeroyd, J.R., Page, N.: The Saxon villages of southern Transylvania: conserving biodiversity in a historic landscape. In: Nature Conservation, pp. 199-210 (2006)

6. Iosif, D.: Ecotourism as a community industry: case study; Transylvanian Saxon communities with fortified churches. Cinq Cont. 1(1), 17-28 (2011)

7. Iorio, M., Corsale, A.: Diaspora and tourism: Transylvanian Saxons visiting the homeland. Tour. Geogr. 15(2), 198-232 (2013)

8. Corsale, A., Iorio, M.: Transylvanian Saxon culture as heritage: insights from Viscri, Romania. Geoforum 52, 22-31 (2014)

9. eHeritage Project Repository. http://www.eheritage.org/category/repository/. Accessed 15 May 2018

10. Duguleana, M., Brodi, R., Girbacia, F., Postelnicu, C., Machidon, O., Carrozzino, M.: Timetravelling with mobile augmented reality: a case study on the Piazza dei Miracoli. In: Ioannides, M., et al. (eds.) EuroMed 2016, Part I. LNCS, vol. 10058, pp. 902-912. Springer, Cham (2016). https://doi.org/10.1007/978-3-319-48496-9_73

11. Santos, M.E.C., Polvi, J., Taketomi, T., Yamamoto, G., Sandor, C., Kato, H.: Toward standard usability questionnaires for handheld augmented reality. IEEE Comput. Graph. Appl. 35(5), 66-75 (2015)

Open Access This chapter is licensed under the terms of the Creative Commons Attribution 4.0 International License (http://creativecommons.org/licenses/by/4.0/), which permits use, sharing, adaptation, distribution and reproduction in any medium or format, as long as you give appropriate credit to the original author(s) and the source, provide a link to the Creative Commons licence and indicate if changes were made.

The images or other third party material in this chapter are included in the chapter's Creative Commons licence, unless indicated otherwise in a credit line to the material. If material is not included in the chapter's Creative Commons licence and your intended use is not permitted by statutory regulation or exceeds the permitted use, you will need to obtain permission directly from the copyright holder.

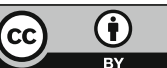

